\begin{tabular}{|c|l|}
\hline Title & Silver Embedded Nanomesas as Enhanced Single Quantum Dot Emitters in the Telecommunication C Band \\
\hline Author(s) & Huh, Jae Hoon; Hermannstädter, Claus; A kahane, Kouichi; Jahan, Nahid A .; Sasaki, Masahide; Suemune, Ikuo \\
\hline Citation & $\begin{array}{l}\text { Japanese Journal of A pplied Physics, 51, 06FF12 } \\
\text { https://doi.org/10.1143/JAP.51.06FF12 }\end{array}$ \\
\hline Issue Date & 2012-06 \\
\hline Doc URL & http://hdl.handle.net/2115/52475 \\
\hline Rights & ○ 2012 The Japan Society of A pplied Physics \\
\hline Type & article (author version) \\
\hline File Information & MN11109.pdf \\
\hline
\end{tabular}

Instructions for use 


\title{
Silver Embedded Nanomesas as Enhanced Single Quantum Dot Emitters in the Telecommunication C Band
}

\author{
Jae-Hoon HUH ${ }^{1,3^{*}}$, Claus HERMANNSTÄDTER ${ }^{1}$, Kouichi AKAHANE ${ }^{2}$, Nahid A. \\ JAHAN $^{1}$, Masahide SASAKI ${ }^{2}$, and Ikuo SUEMUNE ${ }^{1}$ \\ ${ }^{1}$ Research Institute for Electronic Science, Hokkaido University, Sapporo 001-0021, Japan \\ ${ }^{2}$ National Institute of Information and Communications Technology, Koganei, Tokyo 184-8795, Japan \\ ${ }^{3}$ Alternative affiliation: Ulsan National Institute of Science and Technology, Ulsan 689-798, Korea \\ *E-mail address: hjaehoon@ unist.ac.kr
}

\begin{abstract}
We use high-density InAs quantum dots, which were grown by molecular beam epitaxy on $\operatorname{InP}(311) B$ substrates, as photon sources in the telecommunication $\mathrm{C}$ band at approximately $1.55 \mu \mathrm{m}$. To select a small numbers of dots, we fabricate sub-micrometer sized mesas by electron beam lithography and reactive ion etching. The benefit of using high-density quantum dot samples is that at least one optically active quantum dot can be expected in every single mesa. We show that the etching rate and resulting mesa shape of the $\operatorname{In}_{0.53} \mathrm{Al}_{0.22} \mathrm{Ga}_{0.25} \mathrm{As}$ epitaxial layer can be varied with the chamber pressure during the etching process. Furthermore, under constant pressure and with increasing etching time, the sequential etching of the epitaxial layer and the underneath substrate leads to a significant modification in the mesa shape, too. We demonstrate that the isolation of a small number of quantum dots within one mesa results in the appearance of single quantum dot emission with a narrow line width and minimal spectral overlap between different emission lines. We moreover present significant enhancement of the luminescence collected from single dots in silver-embedded nanomesas when compared with as-etched mesas.
\end{abstract}




\section{Introduction}

Semiconductor quantum dot (QD)-based single photon or entangled photon pair sources are promising candidates for applications in quantum information processing and communication. ${ }^{1,2)}$ Global communication infrastructure requires device operation within the telecommunication $\mathrm{C}$ band (conventional band: 1.530 to $1.565 \mu \mathrm{m}$ ). This wavelength range is favorable for lowest-loss transmission in fiber networks, which is an essential prerequisite for efficient operation with a low bit-error rate. However, up to now, most reported single photon emitters have been below $1.3 \mu \mathrm{m}$ wavelength. ${ }^{3-8)}$ Extremely low density InAs or InAs/InGaAs QDs on GaAs substrates were reported at wavelengths up to $1.4 \mu \mathrm{m}$, which is the limit on these substrates. ${ }^{9-11)}$ InAs QDs grown on InP substrates, however, allow the growth of QDs with substantially longer emission wavelengths; tunable wavelength was reported between 1.3 and $1.7 \mu \mathrm{m}^{12-14)}$ Several compounds were used as buffer layers to investigate the growth of InAs QDs (or other nanostructures) on InP substrates, such as InP, ${ }^{15)}$ InAlAs, ${ }^{16)}$ InGaAs, ${ }^{17)}$ InGaAsP, ${ }^{18)}$ and InGaAlAs. ${ }^{19-21)}$ We want to highlight the difference in some properties of QDs grown on the two substrate orientations, the more widely used (100) orientation and the (311)B orientation. The deposition of InAs QDs on such buffer layers on $\operatorname{InP}(311) B$ leads to QD sizes that are approximately two times smaller than QDs grown on $\operatorname{InP}(100)$ substrates. Furthermore, the QD density on these higher index number surfaces is up to ten times higher compared to dots grown on $\operatorname{InP}(100){ }^{22,23)}$ The photoluminescence (PL) intensity at $293 \mathrm{~K}$ of InAs QDs grown on $\operatorname{InP}(311) \mathrm{B}$ substrates was five times larger than that of QDs grown on $\operatorname{InP}(100)$ substrates; in both cases, $\operatorname{In}_{0.52} \mathrm{Al}_{0.29} \mathrm{Ga}_{0.19} \mathrm{As}$ capping layers were used. ${ }^{23)}$ The different crystallographic symmetries of the two substrate orientations trigger different symmetries (and morphologies) of the QDs and 
thus lead to different optical properties, such as electron-hole overlap and band mixing as well as exciton fine structure and polarization of the emitted photons. ${ }^{24)}$ Moreover, the height histograms of InAs islands demonstrate that the deposition on high-index surfaces increases the size uniformity of islands. In addition, QD height and lateral size control based on growth and in-situ annealing conditions provides a good strategy to precisely tune the QDs' emission wavelength.

In this work, we highlight that a precise control of the mesa's structural parameters is crucial for the optical access to single QDs. In particular, the modification of the size of the QD containing area is important because it directly allows control of the number of QDs. A dramatic modification from tapered to almost straight nano-mesas can be obtained by changing the etching time, which leads to further reduction of the contained QD number. Furthermore, we demonstrate that the luminescence emitted from single QDs that are located in a silver-embedded nanomesa can be significantly enhanced in the desired collection direction compared with that from QDs in as-etched mesas.

\section{QD Growth and Mesa Fabrication}

High-density QD heterostructures were grown by solid source-molecular beam epitaxy (MBE) on lattice-matched $\operatorname{In}_{0.53} \mathrm{Al}_{0.22} \mathrm{Ga}_{0.25}$ As buffer layers on $\operatorname{InP}(311) \mathrm{B}$ substrates. Larger QDs of nominal six monolayers (MLs) of InAs are selected, which are embedded in the center of a 300-nm-thick $\operatorname{In}_{0.53} \mathrm{Al}_{0.22} \mathrm{Ga}_{0.25} \mathrm{As}$ barrier to ensure emission wavelengths between 1.4 and $1.6 \mu \mathrm{m}$. Figure 1 shows the cross section of this structure (a), an atomic force microscopy (AFM) image of uncapped high-density InAs QDs (b), and the low-temperature PL of the sample at $12 \mathrm{~K}$. A schematic illustration of a nano-mesa $^{25,26)}$ fabricated by electron beam lithography (EBL) and reactive ion 
etching (RIE) is presented in Fig. 1(d). These high density QD samples offer the advantage that a small number of optically active QDs are contained within every single mesa with almost $100 \%$ probability. Furthermore, Fig. 1(d) highlights the structural parameters of a nano-mesa that define its rotationally symmetric geometry: the top diameter, $D_{\mathrm{x}}$, the taper angle, $\alpha$, and the QD plane diameter, $D_{\mathrm{QD}}$, as well as the relative position of the QDs within the mesa.

Various strategies can be employed to reduce $D_{\mathrm{QD}}$ and thus the number of QDs within one mesa; e.g., the reduction of $D_{x}$ for constant $\alpha$, the decrease of $\alpha$ for constant $D_{\mathrm{x}}$, or the simultaneous reduction of both $\alpha$ and $D_{\mathrm{x}}$. The circles in Fig. 1(b) represent $D_{\mathrm{QD}}$ values of 150 and $400 \mathrm{~nm}$ and show one order of magnitude difference in the QD number. Note that the number of optically active dots varies from the basic QD count because dots located in the vicinity of the mesa surface - or interface with the embedding material - are usually rendered optically dark owing to additional nonradiative decay channels. Furthermore, with a reduced number of dots within the same spectral distribution, or ensemble line width, the spectral overlap of their PL can be minimized. In other words, a sufficiently small number of optically active QDs can be selected as emitters, which leads to an easier optical access to single QDs.

The mesa structures were fabricated in accordance with the six step process, which was introduced for the 4 ML InAs QDs forming the optically active layer and is described in detail elsewhere. ${ }^{25,26)}$ The negative tone resist hydrogen silsesquioxane (HSQ) was used for the EBL of differently sized mesas and arrays of different densities. Patterns of 100 to $300 \mathrm{~nm}$ mesas, with separations between 0.8 and $10 \mu \mathrm{m}$ were written on the resist with individually adjusted different exposure amounts by $100 \mathrm{keV}$ EBL. The $\mathrm{SiO}_{2}$ mask layer was dry etched using $\mathrm{RIE}$ with $\mathrm{CHF}_{3}$ etching gas. Subsequently, 
the InAs/ $/ \mathrm{In}_{0.53} \mathrm{Al}_{0.22} \mathrm{Ga}_{0.25} \mathrm{As}$ epitaxial layer and the InP substrate were dry etched using inductively coupled plasma (ICP)-RIE with $\mathrm{Cl}_{2}$ etching gas. Pattern writing on the resist, $\mathrm{SiO}_{2}$ mask etching, $\mathrm{In}_{0.53} \mathrm{Al}_{0.22} \mathrm{Ga}_{0.25} \mathrm{As} / \mathrm{InP}$ semiconductor etching and $\mathrm{SiO}_{2}$ mask removal were performed one after the other to fabricate the mesa structures. A fieldemission scanning electron microscope (FESEM) equipped with a dimension measurement tool (JEOL JSM-6700FT) was used to determine important parameters, such as $D_{\mathrm{x}}, D_{\mathrm{QD}}, \alpha$, and the etching rates of the epitaxial layer and the substrate (Fig. 2). Table I summarizes the differences in these parameters extracted from $\operatorname{In}_{0.53} \mathrm{Al}_{0.22} \mathrm{Ga}_{0.25} \mathrm{As}$ mesas when relatively low chamber pressures between 0.03 and 0.2 Pa were applied. As the chamber pressure increases, $\alpha$ gradually reduces from 26 to $20^{\circ}$, while the etching rate rapidly increases by almost four times. The reduction of $\alpha$ is considered to be the result of the difference in isotropic etching regarding the reactivity between chloride gas and the ratio of the aluminum (or/and indium) component of the etched semiconductor. ${ }^{27)}$ As distinct evidence of this reactivity, the increase in etching rate with pressure simultaneously contributes to an improved surface morphology; e.g., the etched semiconductor becomes smoother, as reported for InAlAs elsewhere. ${ }^{28)}$ Meanwhile, in the etching process of the epitaxial layer, the diameter reduction of $D_{\mathrm{x}}$ can be strongly related to mask shapes with larger $\alpha$ (of both $\mathrm{SiO}_{2}$ and resist) at a lower chamber pressure. ${ }^{25)}$ These tapered mask shapes can be a key element to reduce the $D_{\mathrm{x}}$ of mesas, as explained in the schematic mechanism in the case of a metal mask in ref. 29. At $0.2 \mathrm{~Pa}$ chamber pressure, $D_{\mathrm{x}}$ appears almost unchanged during epitaxial layer etching; nevertheless, it is essential to carry out further research on the reasons for the substantial modifications as well as the acceleration of the etching rates and the combined etching of epitaxial ternary/quaternary layers and the InP substrate. 
Further continuous etching of the epitaxial layer and substrate results in a further reduction of the mesa taper angle as described below and, therefore, in an easier curtailment of $D_{\mathrm{QD}}$. It thus offers a direct approach to adjust the QD number contained in a mesa. All the arrays of different taper angles and heights shown in Fig. 2 were fabricated under the same etching conditions; that is, room temperature using $\mathrm{Cl}_{2}$ gas with a flow rate of $0.8 \mathrm{sccm}$ with the addition of $0.1 \mathrm{sccm}$ Ar and a gas pressure of 0.2 $\mathrm{Pa}$, an ICP power of $100 \mathrm{~W}$ and a bias power of $300 \mathrm{~W}$. The Ar at a low flow rate was added to provide a more stable plasma generation, particularly under low chamber pressure. To ensure comparable conditions, the Ar flow was maintained constant for all used chamber pressure.

For a short etching time (78 s), where mainly the $\operatorname{In}_{0.53} \mathrm{Al}_{0.22} \mathrm{Ga}_{0.25} \mathrm{As}$ layer is etched [Fig. 2(a)], $\alpha=20^{\circ}$ and $D_{\mathrm{x}}=298 \mathrm{~nm}$, which is almost consistent with the CAD specified and EBL drawn size. At an intermediate stage after $120 \mathrm{~s}$ etching time, which already includes the etching of the InP substrate [Fig. 2(b)], $\alpha$ is reduced to $13^{\circ}$ and $D_{\mathrm{x}}$ to $209 \mathrm{~nm}$. At the final stage after $180 \mathrm{~s}$ of etching [Fig. 2(c)], $D_{\mathrm{x}}$ is reduced to $105 \mathrm{~nm}$ and $D_{\mathrm{QD}}$ to $156 \mathrm{~nm}$. The taper angle of the $\operatorname{In}_{0.53} \mathrm{Al}_{0.22} \mathrm{Ga}_{0.25}$ As part is $8^{\circ}$, whereas that for the InP substrate part is only $3^{\circ}$. The structural parameters of these three samples are summarized in Table II.

\section{Results and Discussion}

Table II shows that $D_{\mathrm{x}}, D_{\mathrm{QD}}$ and the taper angles of an as-etched mesa containing two intermediate steps on the epitaxial layer and the substrate. The three parameters show sharp decrease although the average vertical etching rate is almost constant in the range of 4.0 to $4.2 \mathrm{~nm} / \mathrm{s}$. By subtracting the $\operatorname{In}_{0.53} \mathrm{Al}_{0.22} \mathrm{Ga}_{0.25} \mathrm{As}$ part from this average 
etching rate, the InP etching rate is estimated to be 4.5 to $5.0 \mathrm{~nm} / \mathrm{s}$, which is faster than the $3.8 \mathrm{~nm} / \mathrm{s}$ of the $\operatorname{In}_{0.53} \mathrm{Al}_{0.22} \mathrm{Ga}_{0.25} \mathrm{As}$. But the lateral etching rate of the mesa is estimated to be $1.1 \mathrm{~nm} / \mathrm{s}$. From these estimated values, we can conclude that the slower lateral etching dominates the geometry of the 300 -nm-thick $\operatorname{In}_{0.53} \mathrm{Al}_{0.22} \mathrm{Ga}_{0.25} \mathrm{As}$ epitaxial layer. For longer etching times the faster vertical etching transforms the geometry of both the epitaxial layer and the underneath InP substrate. Furthermore, the reduction of $D_{\mathrm{x}}$ for the prolonged etching time indicates the continuous diameter reduction of the resist mask. In particular, the modification of $\alpha$, which is due to the different intrinsic material properties of $\operatorname{In}_{0.53} \mathrm{Al}_{0.22} \mathrm{Ga}_{0.25} \mathrm{As}$ and $\mathrm{InP}$, is of interest. Examples for other previously reported results for InP etching are: fluorine RIE resulting in very rough surfaces and low etching rates on $\mathrm{InP}^{30)}$ and $\mathrm{Cl}_{2} / \mathrm{Xe}$ mixed gas ICP leading to vertical and smooth etch profiles with a $\mathrm{Cl}_{2}$-based ICP etch process at approximately $200{ }^{\circ} \mathrm{C} .{ }^{31}$ )

Ultimately, with the structure presented in Fig. 2(c) we determined a final sample to implement our research purpose owing to an attractively small $D_{\mathrm{QD}}$ combined with a very clean and uniform mesa surface. The InP surface roughness between the mesas does not influence the quality of the nanostructures; however, the mesa surface roughness needs to be carefully controlled when a metal, especially silver is used as a reflector surrounding the mesa. It is essential to reduce the roughness of the reflective silver surface to minimize losses due to surface plasmons and to ensure good optical properties of the QDs. ${ }^{32)}$ To circumvent the impact of a not perfectly smooth semiconductor surface on the semiconductor-metal interface roughness, we inserted a 60-nm-thick $\mathrm{Si}_{3} \mathrm{~N}_{4}$ dielectric interfacial layer before the deposition of 3 to $5 \mu \mathrm{m}$ silver by electron beam deposition. The evaporated silver reflector was selected to provide the highest reflectivity from $633 \mathrm{~nm}$ (high-energy photoexcitation) to the near-infrared 
spectral range of 1.3 to $1.6 \mu \mathrm{m}$ (QD PL), which is our main interest, rather than any other metal (like gold or aluminum). ${ }^{33)}$ Silver thus has the potential for the highest enhancement of photon extraction along the desired direction. The insulating layer furthermore suppress any electric leakage between the semiconductor layers and the surrounding metal, which would result in PL line width broadening and reduced or completely suppressed radiative recombination. Mesa arrays were fabricated under the aforementioned etching conditions, and obtained at the final stage after $180 \mathrm{~s}$ of etching. Figure 3(a) shows a top view of a large array of good and reproducible quality of almost straight small mesas. Figure 3(b) illustrates the surface appearance of $\mathrm{Si}_{3} \mathrm{~N}_{4} / \mathrm{Ag}$ embedded mesa arrays after turning the sample around and removing the $\operatorname{InP}(311) \mathrm{B}$ substrate by mechanical polishing and chemical etching. ${ }^{25)}$ The QD plain contains approximately ten QDs in each individual mesa and is marked by the red area in the figure inset.

We investigated the optical properties of as-etched and metal-embedded mesas. We performed microscopic PL measurements, where the samples were mounted in a helium-flow cryostat and were cooled to $5 \mathrm{~K}$, under nonresonant excitation with a $\mathrm{HeNe}$ laser $(633 \mathrm{~nm})$. Both the excitation and the PL collection were performed using an $\mathrm{NA}=0.42$ objective lens; the PL was dispersed by a $50 \mathrm{~cm}$ double monochromator using 300 grooves per mm gratings and was detected by a liquid-nitrogen-cooled InGaAs photodiode array detector. The results of these PL measurements are displayed in Fig. 4 as a function of excitation power for an as-etched mesa (a) and a $\mathrm{Si}_{3} \mathrm{~N}_{4} / \mathrm{Ag}$-embedded mesa (b). The silver-embedded structure leads to an enhancement of the detected single QD emission (integrated peak intensities) of approximately 26 times at intermediate power (20\% of the exciton saturation power) and of approximately 30 times at 
saturation power, when compared with the QD PL from the as-etched mesa. Notably, from these small mesas, we observed sharp QD emission with line widths of approximately $100-150 \mu \mathrm{eV}$ full width at half maximum at wavelengths in the $\mathrm{C}$ band at approximately 1.52-1.55 $\mu \mathrm{m}$. In both cases, the spectra feature QD emission from more than one mesa because of the small separation between individual mesas. In particular, this results in a remarkable signal background at the highest shown excitation powers. In the future, the samples for optical investigations will be designed with a larger mesa separation (> $5 \mu \mathrm{m}$ ) to prevent the simultaneous signal collection from more than one mesa. Note that different mesas are shown in Figs. 4(a) and 4(b) because we could not identify the same mesa before and after the metal embedding and substrate removal process steps, because of the rather nonuniform and anisotropic chemical etching of the $\operatorname{InP}(311) \mathrm{B}$ substrates in contrast to other orientations, such as (001). These difficult etching conditions have the result that not all metal-embedded mesas can be used because they might be either covered by a remaining substrate layer and are thus not visible or because they might be located in an area where all semiconductor parts are completely removed. Despite these difficulties, we found and confirmed areas of successfully fabricated silver-embedded mesas with good optical properties and uniform surface appearance as displayed in Fig. 3(b). The QD PL, which is shown in Fig. 4 for comparison between as-etched and metal-embedded mesas, displays different QDs; however, regarding the spectral width of the QD ensemble [Fig. 1(c)], we selected QDs of rather similar emission energies. This ensures that they are likely similar in their morphologies, confinement potentials, strain, etc., and therefore a comparison of the photon extraction remains valid. We have measured tens of different mesas, both as-etched and embedded, and found comparable intensities to the displayed examples 
for all of them.

\section{Conclusions}

We presented the fabrication of $\operatorname{In}_{0.53} \mathrm{Al}_{0.22} \mathrm{Ga}_{0.25} \mathrm{As}$ nano-mesas with small diameters using EBL and RIE. Control of the mesa sizes, shapes, and especially taper angles could be achieved by varying the chamber pressure and changing the etching times. The latter led to a different weight in the combination etching between the contained $\mathrm{In}_{0.53} \mathrm{Al}_{0.22} \mathrm{Ga}_{0.25} \mathrm{As}$ epitaxial layer and the InP substrate part and thus eventually allowed the production of suitable nano-mesas with diameters of the QD area of only around $150 \mathrm{~nm}$. Using these nano-mesas, we could isolate a sufficiently small number of InAs QDs and measure their single-dot emission at approximately $1.5 \mu \mathrm{m}$ and with narrow line widths. In a subsequent processing step, the nano-mesas were embedded in silver, turned around, and the substrate was removed, which resulted in a drastic improvement of the usability of the contained QDs in optical experiments. We demonstrated that embedding the nano-mesas in sliver led to an enhancement of the collected single QD emission of up to 30 times when compared with the as-etched mesas. The presented straight nano-mesas are good candidates for single photon sources in fiber-communication networks.

\section{Acknowledgments}

The authors acknowledge Professor H. Kumano, Dr. H. Sasakura, and Dr. S. Odashima for valuable comments and discussion. This work was supported in part by a Grant-in-Aid for Scientific Research A (No. 21246048), from the Ministry of Education, Culture, Sports, Science and Technology (MEXT), and by the Hokkaido Innovation 
through NanoTechnology Support (HINTS) for nanofabrication. C.H. acknowledges the Japan Society for the Promotion of Science (JSPS) for providing financial support in the form of a JSPS Fellowship for Foreign Researchers; N.A.J. acknowledges financial support via a MEXT scholarship. 


\section{References}

1) Z. Yuan, B. E. Kardynal, R. M. Stevenson, A. J. Shields, C. J. Lobo, K. Cooper, N. S. Beattie, D. A. Ritchie, and M. Pepper: Science 295 (2002) 102.

2) C. L. Salter, R. M. Stevenson, I. Farrer, C. A. Nicoll, D. A. Ritchie, and A. J. Shields: Nature 465 (2010) 594.

3) C. Santori, D. Fattal, J. Vučkovic, G. S. Solomon, and Y. Yamamoto: Nature 419 (2002) 594.

4) I. Friedler, C. Sauvan, J. P. Hugonin, P. Lalanne, J. Claudon, and J. M. Gérard: Opt. Express 17 (2009) 2095.

5) M. B. Ward, T. Farrow, P. See, Z. L. Yuan, O. Z. Karimov, A. J. Bennett, A. J. Shields, P. Atkinson, K. Cooper, and D. A. Ritchie: Appl. Phys. Lett. 90 (2007) 063512. 6) N. Akopian, N. H. Lindner, E. Poem, Y. Berlatzky, J. Avron, D. Gershoni, B. D. Gerardot, and P. M. Petroff: Phys. Rev. Lett. 96 (2006) 130501.

7) M. Pelton, C. Santori, J. Vučković, B. Zhang, G. S. Solomon, J. Plant, and Y. Yamamoto: Phys. Rev. Lett. 89 (2002) 233602.

8) P. M. Intallura, M. B. Ward, O. Z. Karimov, Z. L. Yuan, P. See, P. Atkinson, D. A. Ritchie, and A. J. Shields: J. Opt. A: Pure Appl. Opt. 11 (2009) 054005.

9) L. Seravalli, G. Trevisi, P. Frigeri, D. Rivas, G. Muňoz-Matutano, I. Suárez, B. Alén, J. Canet-Ferrer, and J. P. Martínez-Pastor: Appl. Phys. Lett. 98 (2011) 173112.

10) C. Zinoni, B. Alloing, C. Monat, V. Zwiller, L. H. Li, A. Fiore, L. Lunghi, A. Gerardino, H. De Riedmatten, H. Zbinden, and N. Gisin: Appl. Phys. Lett. 88 (2006) 131102.

11) J.-F. He, H.-L. Wang, X.-J. Shang, M.-F. Li, Y. Zhu, L.-J. Wang, Y. Yu, H.-Q. Ni, Y.-Q. Xu, and Z.-C. Niu: J. Phys. D 44 (2011) 335102. 
12) A. Martinez, K. Merghem, S. Bouchoule, G. Moreau, A. Ramdane, J.-G. Provost, F. Alexandre, F. Grillot, O. Dehaese, R. Piron, and S. Loualiche: Appl. Phys. Lett. 93 (2008) 021101.

13) Q. Gong, R. Nötzel, P. J. van Veldhoven, T. J. Eijkemans, and J. H. Wolter: Appl. Phys. Lett. 84 (2004) 275.

14) P. Caroff, C. Paranthoen, C. Platz, O. Dehaese, H. Folliot, N. Bertru, C. Labbé, R. Piron, E. Homeyer, A. Le Corre, and S. Loualiche: Appl. Phys. Lett. 87 (2005) 243107.

15) S. Barik, H. H. Tan, C. Jagadish, N. Vumirović, and P. Harrison: Appl. Phys. Lett. 88 (2006) 193112.

16) H. Li, J. Wu, B. Xu, J. Liang, and Z. Wang: Appl. Phys. Lett. 72 (1998) 2123.

17) J. Brault, M. Gendry, G. Grenet, G. Hollinger, Y. Desières, and T. Benyattou: Appl. Phys. Lett. 73 (1998) 2932.

18) W. G. Jeong, P. D. Dapkus, U. H. Lee, J. S. Yim, D. Lee, and B. T. Lee: Appl. Phys. Lett. 78 (2001) 1171.

19) T. Mensing, L. Worschech, R. Schwertberger, J. P. Reithmaier, and A. Forchel: Appl. Phys. Lett. 82 (2003) 2799.

20) K. Akahane, N. Yamamoto, and M. Tsuchiya: Appl. Phys. Lett. 93 (2008) 041121.

21) H. Li, T. Daniels-Race, and M.-A. Hasan: Appl. Phys. Lett. 80 (2002) 1367.

22) S. Fréchengques, N. Bertru, V. Drouot, B. Lambert, S. Robinet, S. Loualiche, D. Lacombe, and A. Ponchet: Appl. Phys. Lett. 74 (1999) 3356.

23) H. Saito, K. Nishi, and S. Sugou: Appl. Phys. Lett. 78 (2001) 267.

24) C. Cornet, A. Schliwa, J. Even, F. Doré, C. Celebi, A. Létoublon, E. Macé, C. Paranthoën, A. Simon, P. M. Koenraad, N. Bertru, D. Bimberg, and S. Loualiche: Phys. Rev. B 74 (2006) 035312. 
25) J.-H. Huh, C. Hermannstädter, K. Akahane, H. Sasakura, N. A. Jahan, M. Sasaki, and I. Suemune: Jpn. J. Appl. Phys. 50 (2011) 06GG02.

26) C. Hermannstädter, N. A. Jahan, J.-H. Huh, H. Sasakura, K. Akahane, M. Sasaki, and I. Suemune: New J. Phys. 14 (2012) 023037.

27) T. Tsuchiya, T. Kitatani, K. Ouchi, H. Sato, and M. Aoki: J. Cryst. Growth 272 (2004) 125.

28) R. Germann, S. Hausser, and J.-P. Reithmaier: Microelectron. Eng. 21 (1993) 345.

29) X. Li, T. Abe, and M. Esashi: Sens. Actuators A 87 (2001) 139.

30) G. F. Doughty, S. Thoms, V. Law, and C. D. W. Wikinson: Vacuum 36 (1986) 803.

31) A. Matsutani, H. Ohtsuki, F. Koyama, and K. Iga: Jpn. J. Appl. Phys. 38 (1999) 4260.

32) S.-K. Kim, H.-S. Ee, W. Choi, S.-H. Kwon, J.-H. Kang, Y.-H. Kim, H. Kwon, and H.-G. Park: Appl. Phys. Lett. 98 (2011) 011109.

33) J. M. Bennet and E. J. Ashley: Appl. Opt. 4 (1965) 221. 


\section{Figure captions}

Fig. 1. (a) Schematic illustration of the unstructured samples, (b) AFM image of the uncapped QD layer on top of the sample (the displayed circles of 150 and $400 \mathrm{~nm}$ diameters illustrate the QD number estimation). (c) PL at $12 \mathrm{~K}$, under nonresonant excitation at $532 \mathrm{~nm}$ showing the $6 \mathrm{ML}$ QD ensemble centered at approximately 1.55 $\mu \mathrm{m}$. (d) Schematic illustration of the cross section of a tapered mesa to highlight the geometry and dimesions.

Fig. 2. SEM images showing the modification of the mesa shape with increasing etching time under the same etching conditions (reactive gas: $\mathrm{Cl}_{2}$, chamber pressure $=$ $0.2 \mathrm{~Pa}, \mathrm{ICP}$ power $=100 \mathrm{~W} /$ bias power $=300 \mathrm{~W}, \mathrm{Cl}_{2}$ flow rate $=0.8 \mathrm{sccm}(+\mathrm{Ar} 0.1$ sccm)): (a) 78, (b) 120, and (c) $180 \mathrm{~s}$. The red lines and blue arrows indicate $D_{\mathrm{QD}}$ and the interface between epitaxial InGaAlAs and the substrate, respectively.

Fig. 3. (a) SEM image of an as-etched mesa array and close-up view of an individual mesa (reactive gas: $\mathrm{Cl}_{2}$, chamber pressure $=0.2 \mathrm{~Pa}$, ICP power $=100 \mathrm{~W} /$ bias power $=$ $300 \mathrm{~W}, \mathrm{Cl}_{2}$ flow rate $=0.8 \mathrm{sccm}(+\mathrm{Ar} 0.1 \mathrm{sccm})$, etching time $\left.=180 \mathrm{~s}\right)$. (b) SEM image of the silver embedded mesa array and schematic illustration of an individual silverembedded mesa. The red line and circle in the insets indicate the QD location.

Fig. 4. PL spectra of $6 \mathrm{ML}$ QDs contained in $D_{\mathrm{QD}}=150 \mathrm{~nm}$ mesas at $4 \mathrm{~K}$ under nonresonant excitation at $633 \mathrm{~nm}$ of (a) as-etched mesas and (b) silver-embedded mesas. The PL spectra are displayed for three excitation powers, high power (saturation of the exciton emission), medium power (20\% of the saturation power), and low power ( $5 \%$ of 
the saturation power); note that both power series are displayed on different intensity scales for better visibility of the low signal in (a). 
Table I. Chamber pressure dependence of $0.3-\mu$-thick $\operatorname{In}_{0.53} \mathrm{Al}_{0.22} \mathrm{Ga}_{0.25} \mathrm{As}$ epitaxial layer etching (reactive gas: $\mathrm{Cl}_{2}$, ICP power $=100 \mathrm{~W} /$ bias power $=300 \mathrm{~W}, \mathrm{Cl}_{2}$ flow rate $=0.8 \mathrm{sccm}(+\operatorname{Ar} 0.1 \mathrm{sccm}))$.

Table II. Etching time dependence of continuous etching of epitaxial $\mathrm{In}_{0.53} \mathrm{Al}_{0.22} \mathrm{Ga}_{0.25} \mathrm{As}$ layer and InP substrate (reactive gas: $\mathrm{Cl}_{2}$, chamber pressure $=0.2 \mathrm{~Pa}$, $\mathrm{ICP}$ power $=100 \mathrm{~W} /$ bias power $=300 \mathrm{~W}, \mathrm{Cl}_{2}$ flow rate $\left.=0.8 \mathrm{sccm}(+\mathrm{Ar} 0.1 \mathrm{sccm})\right)$.

Table I. (2 col.)

\begin{tabular}{cccccccc}
$\begin{array}{c}\text { Chamber } \\
\text { pressure } \\
(\mathrm{Pa})\end{array}$ & $\begin{array}{c}\mathrm{CAD} \\
\text { diameter } \\
(\mathrm{nm})\end{array}$ & $\begin{array}{c}\mathrm{D}_{\mathrm{x}} \\
(\mathrm{nm})\end{array}$ & $\begin{array}{c}\mathrm{D}_{\mathrm{QD}} \\
(\mathrm{nm})\end{array}$ & $\begin{array}{c}\alpha^{\text {a) }} \\
(\text { deg. })\end{array}$ & $\begin{array}{c}\text { Height } \\
(\mathrm{nm})\end{array}$ & $\begin{array}{c}\text { Etching } \\
\text { rate }(\mathrm{nm} / \mathrm{s})\end{array}$ & $\begin{array}{c}\text { Etching } \\
\text { time }(\mathrm{s})\end{array}$ \\
\hline 0.03 & 300 & 265 & 410 & 26 & 309 & 0.9 & 360 \\
0.05 & 300 & 271 & 411 & 25 & 288 & 1.0 & 300 \\
0.1 & 300 & 282 & 397 & 21 & 298 & 1.7 & 180 \\
0.2 & 300 & 298 & 407 & 20 & 250 & 3.8 & 65 \\
\hline
\end{tabular}

a) InGaAlAs

Table II. ( 2 col.)

\begin{tabular}{cccccccc}
$\begin{array}{c}\text { Etching } \\
\text { time }(\mathrm{s})\end{array}$ & $\begin{array}{c}\mathrm{CAD} \\
\text { diameter } \\
(\mathrm{nm})\end{array}$ & $\begin{array}{c}\mathrm{D}_{\mathrm{x}} \\
(\mathrm{nm})\end{array}$ & $\begin{array}{c}\mathrm{D}_{\mathrm{QD}} \\
(\mathrm{nm})\end{array}$ & $\begin{array}{c}\alpha^{\mathrm{a})} \\
(\mathrm{deg} .)\end{array}$ & $\begin{array}{c}\alpha^{\mathrm{b})} \\
(\text { deg. })\end{array}$ & $\begin{array}{c}\text { Total } \\
\text { height }^{\mathrm{c})} \\
(\mathrm{nm})\end{array}$ & $\begin{array}{c}\text { Etching } \\
\text { rate }^{\mathrm{c}}{ }^{2} \\
(\mathrm{~nm} / \mathrm{s})\end{array}$ \\
\hline 78 & 300 & 298 & 400 & 20 & 19 & 350 & 4.0 \\
120 & 300 & 209 & 270 & 13 & 10 & 510 & 4.2 \\
180 & 300 & 105 & 156 & 8 & 3 & 760 & 4.2 \\
\hline
\end{tabular}
a) InGaAlAs
b) $\operatorname{InP}$
c) InGaAlAs + InP 
Figure 1 (1 col., Color online)
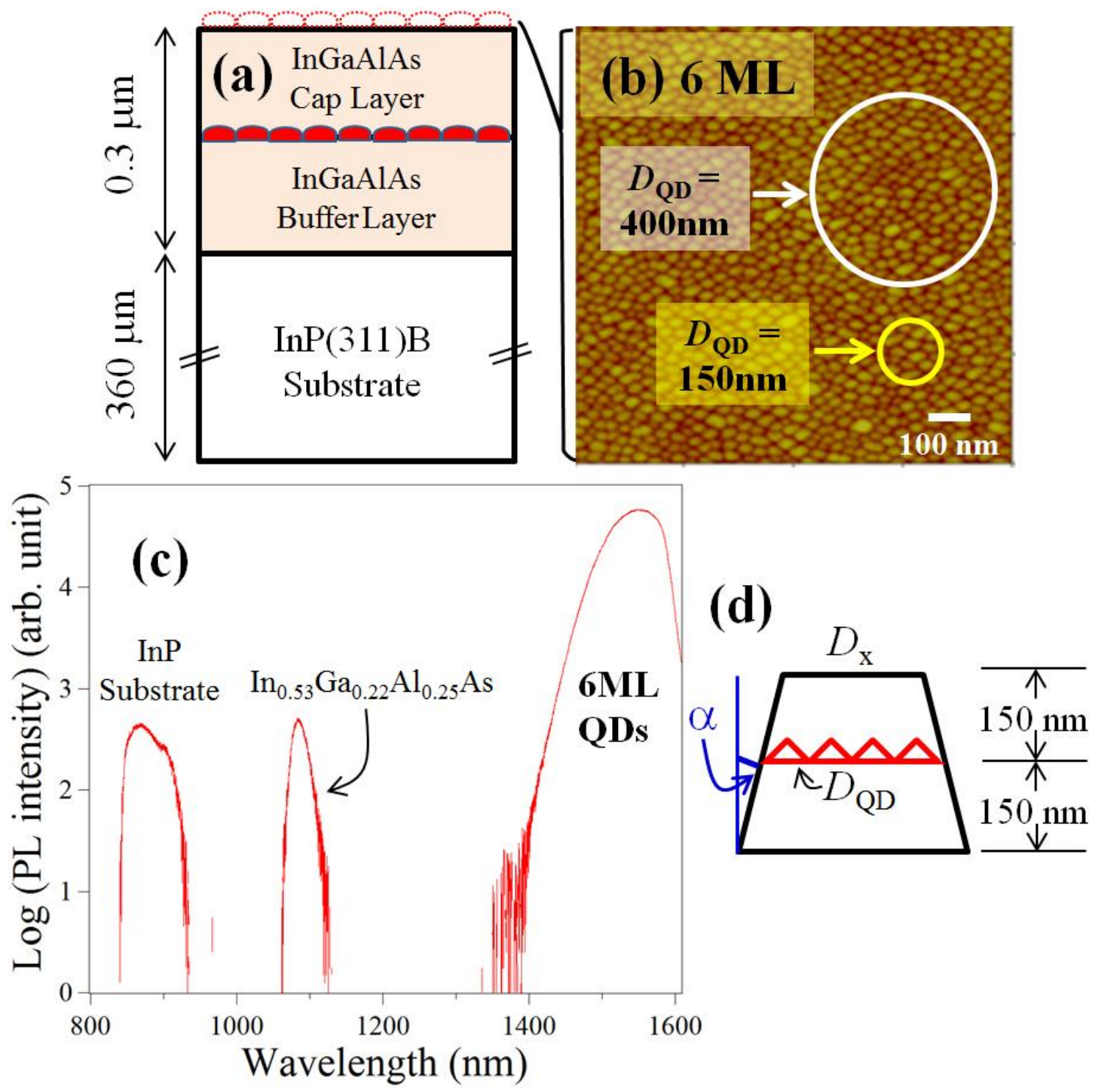
Figure 2 ( 2 col., Color online)
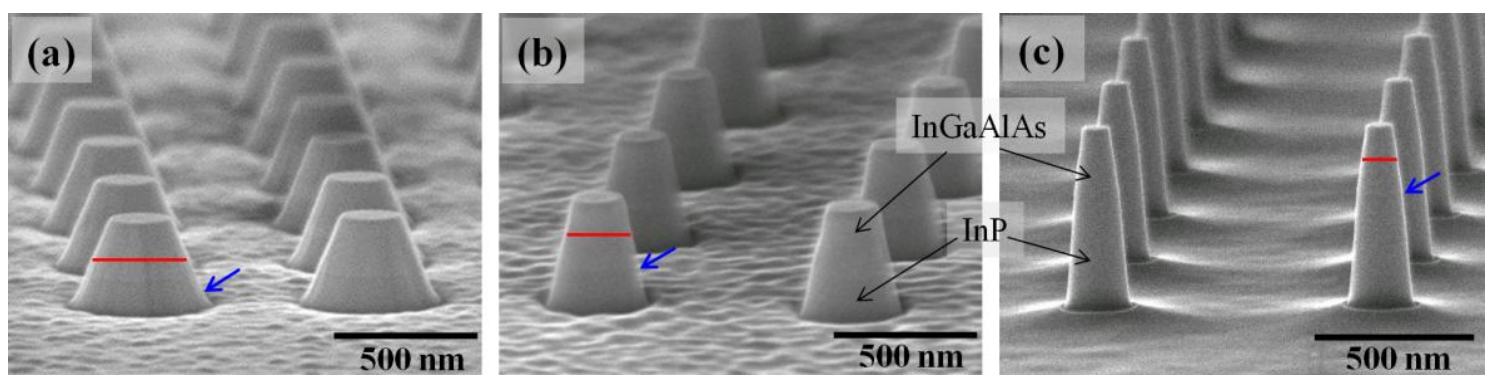
Figure 3 ( 2 col., Color online)

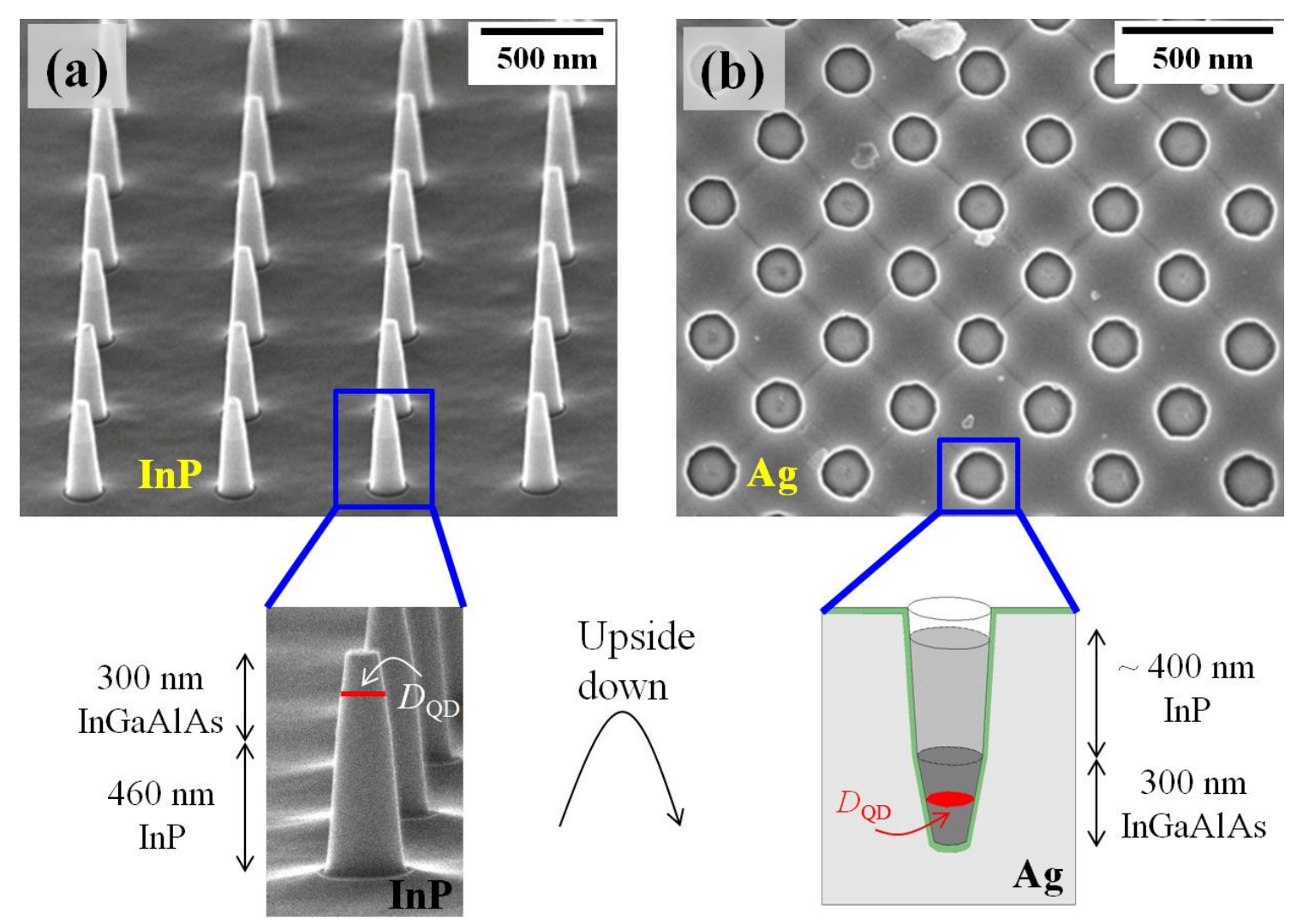


Figure 4 ( 2 col., Color online)
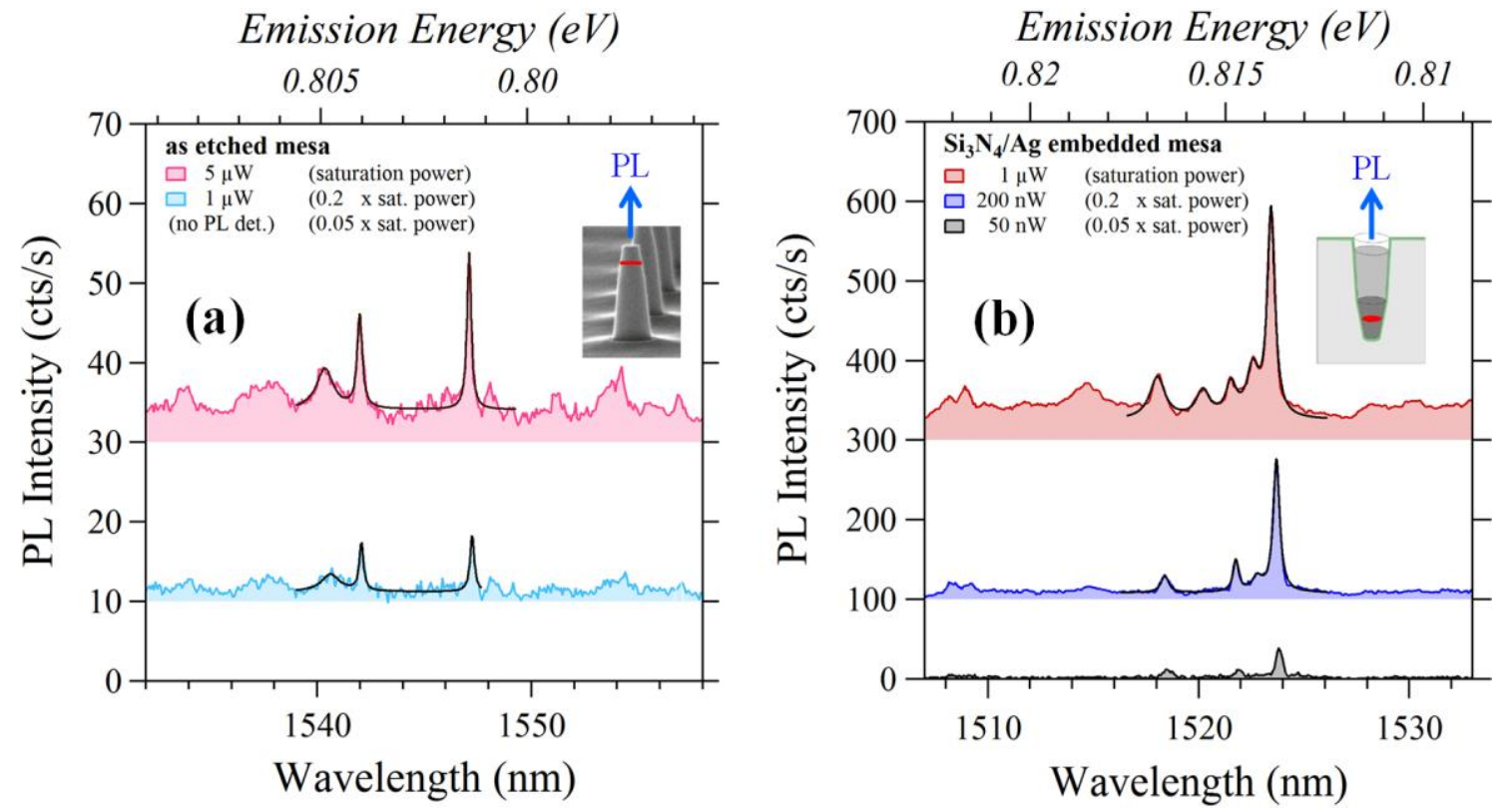